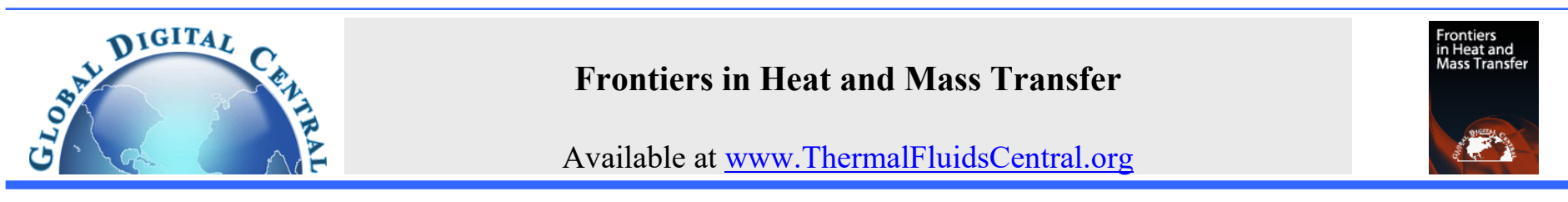

\title{
HEAT PIPE TURBINE VANE INTEGRATION IN GAS TURBINE ENGINES
}

\author{
Michael Petrucci, Amir Faghri* \\ Department of Mechanical Engineering, University of Connecticut, Storrs, Connecticut, 06269, USA
}

\begin{abstract}
The results of integrating heat pipes into the vanes of a turbofan engine are presented. These Heat Pipe Turbine Vanes (HPTV) are integrated into the compressor exit, turbine inlet, and exhaust flow for vane cooling and waste heat recovery. Thermodynamic analysis of HPTV turbofan engines is done and comparisons are made between heat pipe turbine vane cooling and conventional film cooling techniques. Heat transfer through the vanes is analyzed using a thermal network model. Limitations on the heat transfer caused by various limiting phenomena within the heat pipe are also determined.
\end{abstract}

Keywords: heat pipe, thermal network, turbine vane cooling, gas turbine engine

\section{INTRODUCTION}

Since the invention of the turbofan engine in the early 20th century, innovations in gas turbine design have significantly improved their power and efficiency at the expense of more extreme operating temperatures. As temperatures within the hot section of modern turbofan engine designs continue to increase, novel airfoil cooling methods are required to improve engine efficiency and reliability.

Most airfoils within the hot gas path of modern turbofan engines maintain safe temperatures through the use of composite materials with ceramic coatings and film cooling, a process by which a film of cooler air from the compressor is layered over the turbine airfoils (Han et al. 2012). This layer of cool air helps to shield the airfoil from the hot gas flow, and can reduce heat transfer from the hot gas flow to the blade by as much as $50 \%$ (Louis et al. 1983). Film cooling is often paired with internal cooling methods such as impingement, ribbed channel, and pin fins cooling (Bogard and Thole, 2006). However, these cooling methods require a cool air flow to operate. The cool air must be taken from the compressor, which results in the extraction of a significant portion of the compressor discharge air for cooling ( $2.5-4$ percent), having an adverse effect on gas turbine efficiency (Han, 2013). Ejection of this air into the hot gas path results in aerodynamic inefficiencies, and can decrease turbine efficiency by up to $0.8 \%$ (Day et al. 1998). These cooling methods can lead to high temperature gradients across the turbine vane due to uneven cooling, resulting in increased thermal stresses (Han et al. 2012). Additionally, recent trends in the aviation industry have seen an increased interest in alternative fuel sources for gas turbine engines. Airfoils utilizing film cooling must have passages in the surface to allow for cool air to pass through, which prohibits the use of certain alternative fuels that contain particles after combustion that can block these passages (Sundaram and Thole, 2007).

A cooling method utilizing a completely closed system, with no coolant flow, could resolve these inefficiencies. A novel method for closed system turbine vane cooling is integrating heat pipes into the vanes (Faghri, 2016; Zuo et al. 1998). These Heat Pipe Turbine Vanes (HPTV) do not require a coolant film to shield the vane from the hot gas flow, and instead rely on the heat pipe removing sufficient heat from the vane to maintain acceptable component temperatures.

Heat pipes are highly effective heat transfer devices, utilizing the latent heat of an internal working fluid for heat transfer. Heat pipes are completely passive devices, and as such are highly reliable and require little or no maintenance (Faghri and Bergman, 2017; Benn et al. 2016; Faghri, 2016; Shabgard et al. 2015; Faghri, 2012). Conventional heat pipes are composed of a wall, wick, and working fluid in a closed container. The phase change of the working fluid is the primary means of heat transfer, and the wick provides capillary pumping to return the condensed working fluid to the evaporator. Vapor flow is driven by a pressure difference across the heat pipe, while condensate flow is driven by capillary pressure within the wick material. For high temperature applications, such as gas turbine vane cooling, liquid metal working fluids are typically used (Faghri, 2016). At the ranges seen in gas turbine operation, sodium, lithium, and calcium are likely choices for the HPTV working fluid.

Langston and Faghri (1995) suggested three possible HPTV configurations. In Configuration A, a wick structure is inserted into the vane along the interior of the vane wall. This HPTV configuration operates like a conventional heat pipe, utilizing the latent heat of a working fluid to transfer heat between the evaporator and condenser sections. In Configuration B, a central channel with a cooling air flow is inserted into the HPTV. The HPTV is divided into two separate heat pipe sections with the coolant channel in between these sections. The heat pipes transfer heat between the evaporator and condenser sections, and between the wall and internal cooling air channel. This configuration provides additional cooling to the leading and trailing edges, reducing temperature variations across the vane surface. Configuration $\mathrm{C}$ is an annular design with a cooling air passage. The annular geometry allows for an increased heat transfer rate, however fitting the more complex geometry can be difficult. Heat pipe adopted to these geometries are shown in Fig. 1.

Young and Gupta (1980) patented a turbofan engine utilizing HPTV to transfer waste heat from the hot gas stream to the bypass air stream. The design used a ring of vanes in both the hot gas flow and the bypass

\footnotetext{
*Corresponding author.Email: Amir.Faghri@uconn.edu
} 
flow, connected by heat pipes, to transfer heat between the flows. The pressure of the bypass air flow before the HPTV must be greater than that of the hot gas stream before the HPTV for the design to improve performance.
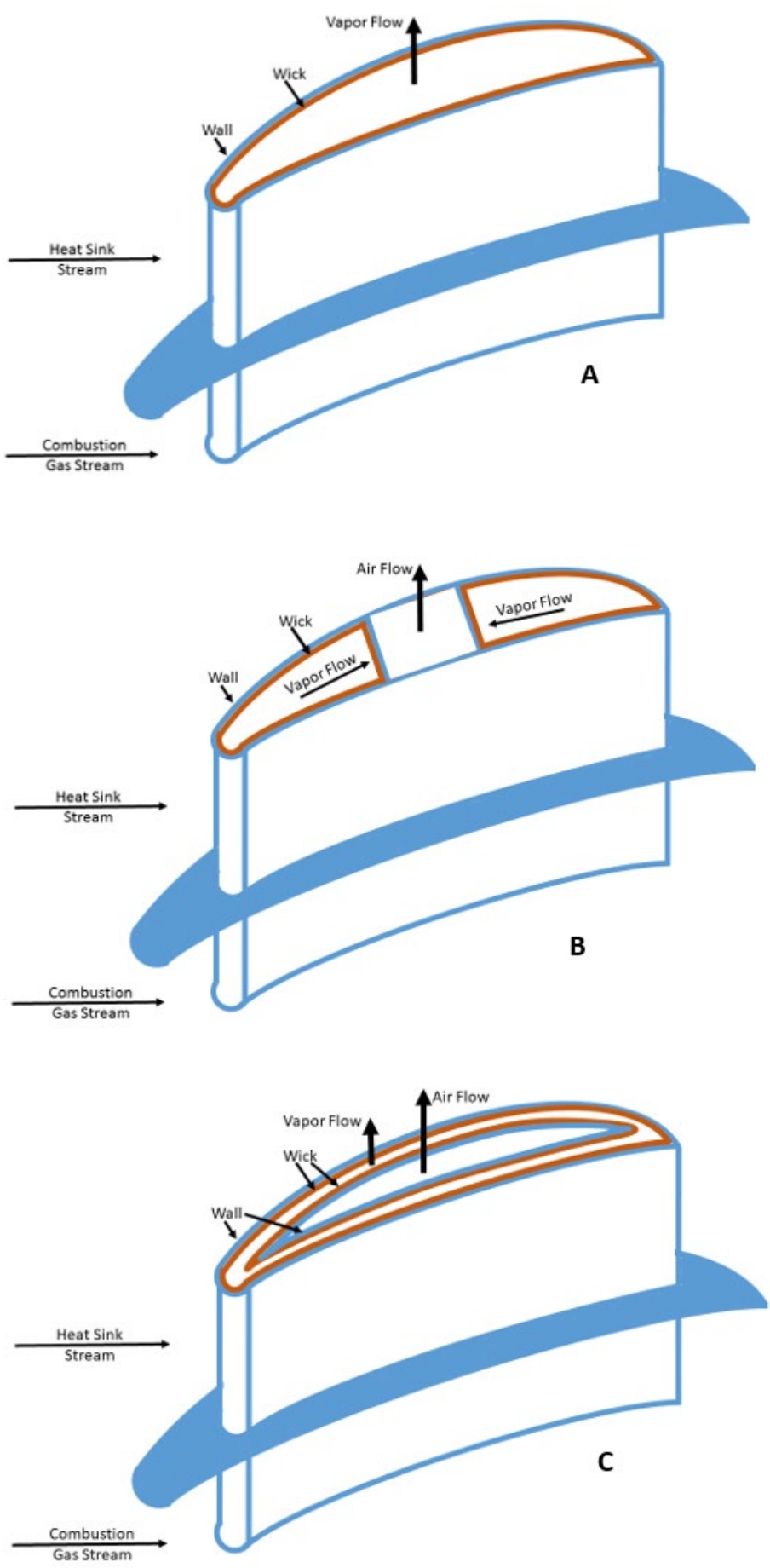

Fig. 1 Heat Pipe Turbine Vane Configurations; A: Conventional, B: Double Wall, C: Annular

Heat pipes within gas turbine engines were discussed by Anderson et al. (1993), including the use of HPTV for turbine inlet vane cooling. The HPTV compressor section was located in the compressor exit guide vanes. A reduction in specific fuel consumption of $1.6 \%$ was found when utilizing HPTV alongside heat pipe endwall cooling. Several additional applications of heat pipes in gas turbines were noted, including turbine blade cooling, engine de-icing, and bearing cooling. The effects of heat removal from the system were not fully considered. Heat transfer analysis was not conducted, as the capillary pumping capacity of the HPTV was used to determine the heat transfer rate. As the capillary pumping pressure is typically not the limiting factor in HPTV, the heat transfer rates obtained by this analysis are likely higher than the actual heat transfer rates.

The use of HPTV was also presented in Silverstein et al. (1994). A military turbofan engine was considered, and HPTV were integrated into the low pressure turbine inlet guide vanes for cooling, with the HPTV condenser sections in the bypass air flow. Preliminary results were compared to those for a film cooling method, and a $0.2 \%$ improvement in specific fuel consumption was found. However, the method for determining HPTV heat transfer considered only the capillary limit within the heat pipe, with no consideration given to other limiting phenomena. Additionally, no heat transfer analysis was made.

Lindemuth and Anderson (1999) patented a concept for heat pipe cooling of turbine vanes. The design features three vapor chambers within the vane, with supporting ribs separating the chambers. An adiabatic section is used to connect the airfoil shaped evaporator to a more conventional box shaped condenser section, outside of the engine and in a cooling air flow.

Zuo et al. (1998) developed a numerical method for analyzing the transient performance of HPTV cooling. Results obtained with the method were compared with experimental results, which validated the model and solutions. Results obtained from the numerical analysis showed that HPTV can successfully complete the startup process, with the metal working fluids transitioning from solid to liquid without heat pipe dryout. These authors developed a detailed numerical model for transient HPTV operation, but did not integrate this model into the gas turbine system to determine the performance impacts of HPTV on the system.

Norris et al. (2011) patented a HPTV system which placed HPTV into the low pressure turbine of a turbofan engine. The condenser section of these vanes consisted of a heat exchanger within the bypass air flow. A flow guide structure is inserted into the bypass flow to direct a sufficient amount of the flow across the HPTV condenser section.

Previous efforts based on conceptual presentations or preliminary analysis of HPTV systems have shown HPTV to be a promising cooling method to improve gas turbine efficiency. As gas turbine operational temperatures continue to rise, the compressor bleed air required for open cycle cooling methods will lead to increased cooling inefficiencies. HPTV provides a more efficient, closed cycle alternative to film and impingement cooling. HPTV are especially suited to use in turbofan engines, as the bypass airflow can provide a source of cooling for the HPTV that is conveniently located, and the energy transferred from the hot gas path to the bypass flow contributes to the thrust generated by the bypass flow.

Three applications of HPTV in turbofan engines are investigated their use in turbine inlet vane cooling, compressor exit vane cooling, and the use of HPTV after the turbine for waste heat recovery. The analysis of HPTV systems is done in two parts - first, a heat transfer analysis of the HPTV, and secondly a thermodynamic analysis of the entire gas turbine system to determine the effects HPTV have on engine thrust and fuel efficiency.

\section{HEAT PIPE TURBINE VANE HEAT TRANSFER}

The HPTV acts as a heat exchanger between the vanes in the hot gas path, and the HPTV condensers placed within the bypass air flow. Heat transfer through the HPTV system was analyzed using a thermal network approach. Shabgard et al. (2015) developed a thermal network model for heat pipe heat exchangers utilizing cylindrical heat pipes. This model was extended to HPTV, including the effects of the airfoil geometry. 
The HPTV geometry used was proposed in Faghri and Langston (1995) as Option \#1, and is shown as Configuration A in Fig. 1.

\subsection{Vane Geometry}

The 11-parameter airfoil geometry developed by Pritchard (1985) was used to model the HPTV. The airfoil is described using five critical points, that are joined in series by either a third order polynomial or an arc. The model developed by Pritchard (1985) describes the outer geometry of the vane and was adapted to include two additional parameters - wall and wick thickness - required for the HPTV cross section. This HPTV design utilizes a uniform wall and wick thickness, however adjusting these values at different points along the vane could improve cooling and lead to a more uniform vane temperature.

This method of developing the vane geometry splits the vane into 5 sections, described by arcs or polynomials - the pressure surface polynomial, suction surface polynomial, suction surface arc, leading edge arc, and trailing edge arc. These sections are further described in Appendix B.

\subsection{Heat Transfer Methodology}

The thermal network model was used to analyze the heat transfer rate through the HPTV, based on the model developed for heat pipe heat exchanger in Shabgard et al. (2015). The full thermal network model of a HPTV system including nomenclature is shown in Fig. 2.

As the airfoil geometry is divided into five distinct sections the thermal resistance across the wall and wick must be calculated for each of these sections independently. These five thermal resistances can then be added in parallel to obtain the thermal resistance of the wall or wick, shown as $R_{\mathrm{w}}$ and $\mathrm{R}_{\mathrm{wk}}$ in Fig. 2.

The heat output into the coolant stream is equal to the heat input into the evaporator section of the HPTV, assuming ideal operation. The heat transfer load required to cool the HPTV can be determined by the convection between the vane and the hot gas flow.

$$
q_{H P T V}=h_{\text {avg }} A_{e}\left(T_{g}-T_{w}\right)
$$

Where $q_{H P T V}$ is the heat transfer rate through the HPTV, $h_{\text {avg }}$ is the average convective heat transfer coefficient, $A_{e}$ is the HPTV evaporator surface area, $T_{g}$ is the hot gas flow temperature, and $T_{w}$ is the acceptable vane wall temperature.

The convective heat transfer coefficient, $h$, will vary across the HPTV. To get the total heat transfer rate, the average heat transfer rate, $h_{\text {avg }}$, should be considered.

Vanes operating in the hot gas flow typically employ a ceramic coating to protect the metal from the high temperature gas flow. The thermal resistance through the ceramic can be added to the external resistance.

$$
q_{H P T V}=\left(h_{\text {avg }} A_{e}+\frac{k_{\text {ceramic }}}{t_{\text {ceramic }}}\right)\left(T_{g}-T_{w}\right)
$$

Where $k_{\text {ceramic }}$ is the thermal conductivity of the ceramic coating, and $t_{\text {ceramic }}$ is the ceramic coating thickness.

\subsection{Heat Transfer Limitations}

The heat transfer rate determined using thermal network analysis neglects several different forms of limiting phenomena, which may result in significantly reduced heat flux than what would be expected from the thermal network results. Limiting phenomena which must be considered include the capillary, sonic, entrainment, condenser, and boiling limitations (Faghri, 2016). The solutions to these limiting phenomena are well known for the cylindrical geometry, and are adopted for a vane geometry.

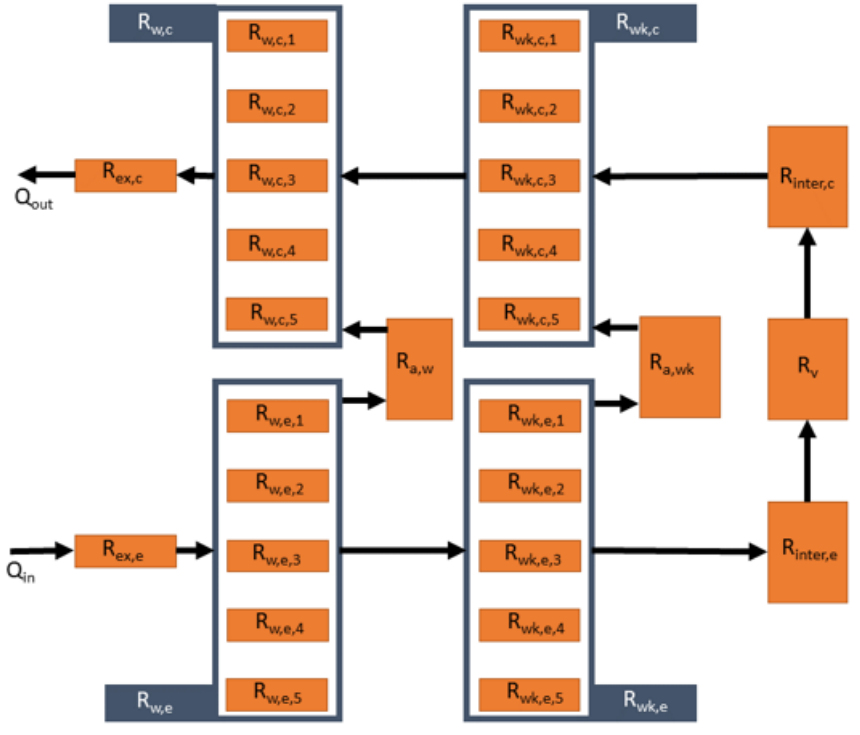

$$
\begin{aligned}
& \text { Rex External Thermal Resistance } \\
& \mathrm{R}_{\mathrm{w}} \quad \text { Radial Wall Thermal Resistance } \\
& \text { Riwk Radial Wick Thermal Resistance } \\
& \mathrm{Ra}_{\mathrm{a}} \quad \text { Axial Thermal Resistance } \\
& \text { Rinter Wick-Vapor Interface Thermal Resistance } \\
& \text { Rx Vapor Thermal Resistance }
\end{aligned}
$$

Fig. 2 Thermal Network Model of a HPTV System

The pumping ability of a capillary (wick) structure is limited. This limitation is referred to as the capillary limit in heat pipes. As this limit is approached, the wick will be unable to return sufficient condensate to the evaporator, limiting heat transport capability. This limit is most dependent on the working fluid used by the heat pipe, and the wick design. Proper wick design can improve capillary pumping ability, avoiding the capillary limit in HPTV.

If the radial heat flux through the heat pipe wall becomes excessively high, nucleation begins to occur in the wick. The boiling of the working fluid can interfere with its circulation, limiting the heat transfer rate. This is referred to as the boiling limit in heat pipes. Boiling is undesirable in wick heat pipes because bubbles will form and block the flow of liquid through the wick. The boiling limit can also be negated through proper wick design in HPTV.

Heat pipes may encounter heat transfer limitations if the vapor velocity reaches the speed of sound inside the heat pipe. This choked working condition is called the sonic limit in heat pipes. Unlike the capillary and boiling limits, the sonic limit is primarily dependent on the geometry of the system, not the wick design. As the geometry of a HPTV system is primarily dependent on the requirements of the external flow, it can be difficult to design the system to improve the sonic limit.

The heat transferred to the HPTV system must be fully removed in the condenser, under steady-state operation. In cases where the condenser heat transfer rate is insufficient, the condenser limit is reached. Silverstein et al. (1995) encountered the condenser limit in their analysis of a HPTV system, and resolved the issue by adding fins external to the HPTV condenser section. The HPTV design patented by Norris et al. (2011) uses a duct in the bypass air flow to ensure sufficient cooling air flows past the condenser. Additional condenser section and coolant flow alterations can ensure sufficient condenser heat transfer rate. 
When the velocity of the vapor becomes sufficiently high, the shear force existing at the liquid-vapor interface may tear the liquid from the wick and entrain it into the vapor stream. This is referred to as the entrainment limit in heat pipes. This phenomenon reduces condensate return to the evaporator, limiting the heat transport capability. While the vapor velocity is primarily tied to the HPTV geometry, the wick can be designed to reduce the impact of entrainment. A composite wick, with a less permeable layer between the liquid and vapor flows, can reduce the impact of entrainment on the system.

Compared to cylindrical heat pipes of a similar size, HPTV encounter the entrainment and sonic limitations at a lower heat transfer rate. This is due to the geometry of the system, as the ratio between the perimeter and the area of a HPTV cross section is much greater than that of a similarly sized cylinder. As such, the sonic and entrainment limitations must be given greater attention than in conventional heat pipe designs.

\section{HPTV THERMOSYNAMIC ANALYSIS}

The effects of HPTV integration can be determined by analyzing the thermodynamics of a turbofan engine with HPTV components. Three applications of HPTV were considered - HPTV turbine inlet guide vanes, HPTV compressor exit vanes, and HPTV for waste heat recovery. An idealized approach was used for the thermodynamic analysis, as the objective is to compare the HPTV and film cooling systems. The flow through the gas turbine was treated as an ideal gas, and the gas turbine components, not including the vanes studied, were considered adiabatic.

\subsection{Turbine Inlet Guide Vanes}

The turbine Inlet Guide Vanes (IGV) experience the highest temperatures in the turbofan engine, as they are the first set of airfoils in the hot gas flow after the combustor. IGV cooling is required to maintain safe airfoil temperatures and prevent large temperature differences across the vane, which can lead to thermal fractures. The cross-section of a turbofan engine with HPTV IGV is shown in Fig. 3.

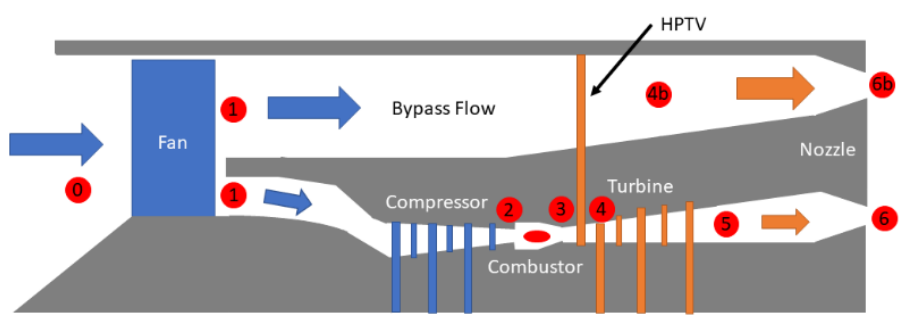

Fig. 3 HPTV Turbine Inlet Guide Vane Cooling in a Turbofan Engine

The turbofan engine was analyzed following the gas path, and the different stages $0-6$ are shown in red circles in Fig. 3 .

Flow properties after the fan can be determined using the fan pressure ratio (FPR) and bypass ratio (BPR).

$$
\begin{gathered}
P_{1}=F P R * P_{0} \\
\dot{m}_{m}=\frac{\dot{m}_{l}}{1+B P R} \\
\dot{m}_{b}=\dot{m}_{l}-\dot{m}_{m} \\
W_{\text {fan }}=\dot{m}_{l}\left(H_{1}-H_{0}\right)
\end{gathered}
$$

Where $P_{0}$ is the atmospheric pressure, $P_{1}$ is the flow pressure after the fan, $F P R$ is the fan pressure ratio, $B P R$ is the engine bypass ratio, $\dot{m}_{i}$ is the inlet mass flow rate, $\dot{m}_{m}$ is the main gas flow mass flow rate, $\dot{m}_{b}$ is the bypass flow mass flow rate, $W_{\text {fan }}$ is the fan work, $H_{0}$ is the inlet enthalpy and $H_{1}$ is the flow enthalpy after the fan. The enthalpy before and after the fan, $H_{0}$ and $H_{1}$, can be determined from the pressure (Bergman and Incropera, 2011).

The compressor exit conditions can be obtained similarly to those of the fan.

$$
\begin{gathered}
P_{2}=C P R * P_{1} \\
W_{\text {comp }}=\dot{m}_{m}\left(H_{2}-H_{1}\right)
\end{gathered}
$$

Where $C P R$ is the compressor pressure ratio, $W_{\text {comp }}$ is the compressor work, $P_{2}$ is the main flow pressure after the compressor, and $\mathrm{H}_{2}$ is the main flow enthalpy after the compressor.

Properties after the combustor can be solved using the known heat input. The system is idealized, as the addition of fuel to the air flow is neglected, and the flow exiting the combustor is assumed to be pure air.

$$
\begin{aligned}
q_{\text {in }} & =\dot{m}_{\text {fuel }} \Delta H_{r} \\
H_{3} & =H_{2}+\frac{q_{\text {in }}}{\dot{m}_{m}}
\end{aligned}
$$

Where $q_{\text {in }}$ is the heat input to the system from combustion, $\dot{m}_{f u e l}$ is the mass flow rate of the fuel, $\Delta H_{r}$ is the lower heating value of the fuel, and $H_{3}$ is the main flow enthalpy after the combustor.

The required cooling, $q_{\text {HPTV }}$, can be determined using Eqs. (1) and (2), substituting $T_{3}$ for $T_{g}$. The change in enthalpy of the main flow and the bypass flow due to heat transfer through the HPTV can be determined with the heat transfer rate and the mass flow rates.

$$
\begin{aligned}
& H_{4}=H_{3}-\frac{q_{H P T V} n}{\dot{m}_{m}} \\
& H_{4 b}=H_{1}+\frac{q_{H P T V} n}{\dot{m}_{b}}
\end{aligned}
$$

Where $H_{4}$ is the enthalpy of the main flow after the HPTV, $n$ is the number of HPTV, and $H_{4 b}$ is the enthalpy of the bypass flow after the HPTV. When the pressure change across the HPTV is determined for the main and bypass flows, a pressure loss factor is included to account for the interruption of the flow by the insertion of the vanes.

The turbine work in a turbofan engine is equal to the sum of the fan and compressor work. This can be used to determine the enthalpy of the flow after the turbine.

$$
\begin{aligned}
W_{t u r b} & =W_{f a n}+W_{c o m p} \\
H_{5} & =H_{4}-\frac{W_{t u r b}}{\dot{m}_{m}}
\end{aligned}
$$

Where $W_{\text {turb }}$ is the turbine work and $H_{5}$ is the enthalpy of the main flow after the turbine.

The velocity of the main and bypass flow after the nozzle is required to calculate the thrust of the engine. The enthalpy of the main and bypass flows after the nozzle can be calculated using the pressure difference across the nozzle. A conversion factor of 1000 is included to convert the enthalpy, in kilojoules, to velocity in meters per second.

$$
\begin{gathered}
V=\sqrt{2000\left(H_{5}-H_{6}\right)} \\
V_{b}=\sqrt{2000\left(H_{5 b}-H_{6 b}\right)} \\
F_{\text {thrust }}=\dot{m}_{m} V+\dot{m}_{b} V_{b}
\end{gathered}
$$

Where $V$ is the final velocity of the main flow, $V_{b}$ is the final velocity of the bypass flow, $H_{6}$ is the enthalpy of the main flow after the nozzle, $H_{6 b}$ is the velocity of the bypass flow after the nozzle, and $F_{\text {thrust }}$ is the thrust of the engine. 


\subsection{Compressor Exit Guide Vanes}

While the compressor operates at significantly lower temperatures than the turbine, increasing pressure ratios can create temperatures high enough at the compressor exit to require cooling. HPTV can be integrated into the compressor exit vanes to provide cooling in a similar fashion to the turbine inlet guide vanes. A HPTV compressor exit vane cooling system is shown in Fig. 4.

The allowable compressor exit temperature can be determined using the heat transfer rate of the HPTV, found using Eqs. (1) and (2).

$$
T_{\text {Comp }, \text { Exit }}=\frac{q_{H P T V} n}{A_{e} h_{\text {avg }}}+T_{w}
$$

Where $h_{a v g}$ is the average convective heat transfer coefficient across the compressor exit vane and $T_{\text {Comp,Exit }}$ is the allowable compressor exit temperature.

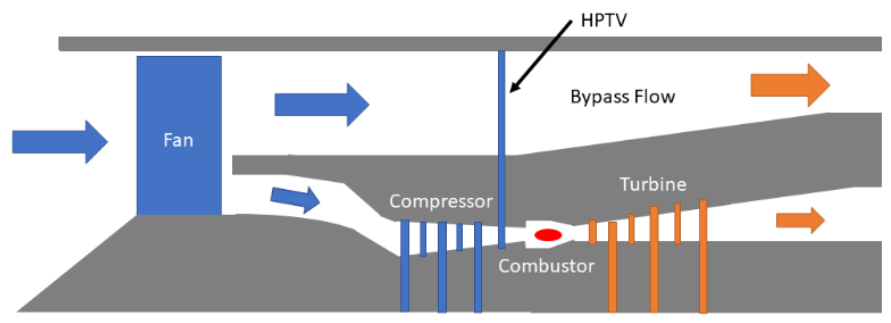

Fig. 4 HPTV Compressor Exit Vane Cooling in a Turbofan Engine

\subsection{Waste Heat Recovery}

Young and Gupta (1980) found that transferring heat from the main stream to the bypass air stream of a turbofan engine can improve performance under certain conditions and patented an engine design using a heat exchanger to do this. A HPTV system based on this concept is investigated, as shown in Fig. 5.

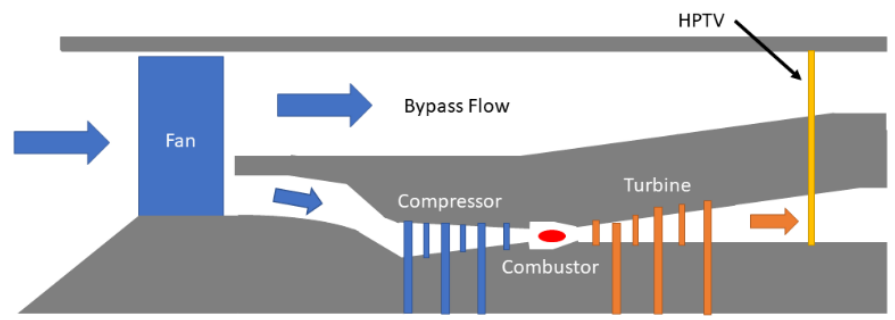

Fig. 5 HPTV for Waste Heat Recovery in a Turbofan Engine

The HPTV design and limitations in the waste heat recovery role differ significantly from those of the IGV and CEV HPTV designs, as the primary goal in waste heat recovery is heat transfer, not cooling. This concept will only improve turbofan engine performance in certain cases, depending on the pressure of the bypass air flow and whether the bypass and main flows are mixed.

\section{RESULTS AND DISCUSSION}

\subsection{Initial Submission}

In the HPTV turbofan engine, the HPTV uses the bypass air flow to cool the HPTV condenser section. This process removes heat from the main gas flow and transfers it into the bypass flow, increasing the thrust provided by the bypass air, while decreasing the energy available in the main gas flow.
The HPTV airfoil must be constructed of a material capable of withstanding the forces within the engine, with a high melting point to decrease the required cooling, and a high thermal conductivity to improve HPTV heat transfer. The HPTV design investigated used a nickel-based alloy, IN-100, as the vane wall material. The properties and aerospace applications of IN-100 and other nickel-based alloys were investigated by Pollock and Tin (2006). A homogeneous screen mesh wick was used, with mesh diameter of $0.2 \mathrm{~mm}$. The working fluid chosen was sodium, due to its ideal properties for heat pipe operation at the desired temperatures. Heat pipe working fluids across a variety of temperature ranges are presented and discussed in Faghri (2016).

The parameters of the turbofan turbine IGV system are presented in Table 1. Convective heat transfer coefficients used include the exterior surface area of the HPTV, as such the units are $\mathrm{kW} / \mathrm{K}$. The method for determining the vane convective heat transfer coefficient is presented in Gauntner and Sucec (1978).

Table 1 HPTV IGV Inputs

\begin{tabular}{|c|c|c|c|}
\hline \multicolumn{4}{|l|}{ System Design Parameters } \\
\hline Fan Pressure Ratio & FPR & 3 & \\
\hline Bypass Ratio & BPR & 1 & \\
\hline Compressor Pressure Ratio & CPR & 16 & \\
\hline \multicolumn{4}{|l|}{ Compressor Inlet Parameters } \\
\hline Temperature & $\mathrm{T}_{0}$ & 225 & $\mathrm{~K}$ \\
\hline Pressure & $\mathrm{P}_{0}$ & 0.265 & Bar \\
\hline Mass Flow Rate & $\dot{\mathrm{m}}$ & 80 & $\mathrm{~kg} / \mathrm{s}$ \\
\hline \multicolumn{4}{|l|}{ Combustor Parameters } \\
\hline Fuel Mass Flow Rate & $\dot{\mathrm{m}}_{\mathrm{f}}$ & 1.6 & $\mathrm{~kg} / \mathrm{s}$ \\
\hline Fuel Lower Heating Value & $\Delta \mathrm{H}_{\mathrm{f}}$ & 45000 & $\mathrm{~kJ} / \mathrm{kg}$ \\
\hline \multicolumn{4}{|l|}{ Turbine Parameters } \\
\hline IGV Convection Coefficient & $\mathrm{h}$ & 0.009 & $\mathrm{~kW} / \mathrm{K}$ \\
\hline Number of HPTV & $\mathrm{n}$ & 60 & \\
\hline Allowable Vane Temperature & $\mathrm{T}_{\mathrm{w}}$ & 1200 & $\mathrm{~K}$ \\
\hline $\begin{array}{l}\text { Isothermal Film Cooling } \\
\text { Effectiveness }\end{array}$ & $\eta_{\text {iso,film }}$ & 40 & $\%$ \\
\hline $\begin{array}{l}\text { Film Cooling Heat Exchanger } \\
\text { Effectiveness }\end{array}$ & $\varepsilon$ & 90 & $\%$ \\
\hline Film Coolant Flow Pressure Loss & ploss,film & 5 & $\%$ \\
\hline Bypass Flow Pressure Loss & ploss,bypass & 2 & $\%$ \\
\hline
\end{tabular}

The engine was also analyzed with the use of film cooling for the IGV, based on the film cooling performance values studied in Kumar and Singh (2008). The engine was studied in flight at an altitude of $10 \mathrm{~km}$. Results of both the HPTV and film-cooled engines are presented in Table 2.

Table 2 HPTV IGV Results

\begin{tabular}{|ccc|}
\hline & HPTV & Film Cooling \\
\hline Thrust $(\mathrm{kN})$ & 69.84 & 68.97 \\
\hline TSFC $\left(\mathrm{kg} / \mathrm{kN} \times 10^{5}\right)$ & 2.29 & 2.32 \\
\hline
\end{tabular}

HPTV resulted in a $1.3 \%$ increase in thrust compared to a film cooling system. This led to a $1.24 \%$ decrease in thrust specific fuel 
consumption (TSFC), a significant improvement in gas turbine fuel efficiency. The reduction in required bleed air from the compressor offered the greatest improvement in efficiency, while the improved turbine efficiency due to the removal of the cool air film was offset by the loss of energy through the HPTV to the bypass air flow.

Heat transfer limitations in the HPTV were calculated to ensure no limiting phenomena occurred that could lead to reduced heat transfer or HPTV dryout. Results of the heat transfer analysis are presented in Table 3.

Table 3 HPTV IGV Heat Transfer Limitations

\begin{tabular}{|lr|}
\hline Limitation & Heat Transfer Limit $(\mathbf{k W})$ \\
\hline Capillary & 7123 \\
\hline Boiling & 76415 \\
\hline Sonic & 150 \\
\hline Entrainment & 8.5 \\
\hline
\end{tabular}

The capillary, boiling, and sonic limitations far exceeded the actual heat transfer rate of $7.7 \mathrm{~kW}$. The entrainment limit is the closest limitation, occurring with a $10 \%$ increase in the heat transfer rate. A composite wick design, with a finer mesh between the vapor flow and liquid flow, could be implemented in the HPTV design if a greater margin is desired between the heat transfer rate and limiting phenomena.

\subsection{Compressor Exit Vanes}

With high gas turbine pressure ratios, the temperature at the compressor exit can approach or exceed material limits. Compressor exit vane (CEV) cooling allows for higher pressure ratios to be achieved, as higher temperatures can be withstood at the compressor exit. The use of heat pipes for compressor exit vane cooling was patented by McGarry (1978). A turbofan engine was analyzed, both with and without HPTV CEV. The system was run at the highest pressure ratio possible without exceeding temperature limits at the compressor exit. Input parameters are shown in Table 4.

Table 4 HPTV CEV Inputs

\begin{tabular}{|llrll|}
\hline System Design Parameters & & & \\
\hline Fan Pressure Ratio & FPR & \multicolumn{1}{l|}{4} & \\
\hline Bypass Ratio & BPR & 0.4 & \\
\hline Compressor Inlet Parameters & & & \\
\hline Temperature & $\mathrm{T}_{0}$ & 225 & $\mathrm{~K}$ \\
\hline Pressure & $\mathrm{P}_{0}$ & 0.265 & $\mathrm{Bar}$ \\
\hline Mass Flow Rate & $\mathrm{m}$ & 90 & $\mathrm{~kg} / \mathrm{s}$ \\
\hline Compressor Exit Parameters & & & \\
\hline Number of CEV & $\mathrm{n}$ & 60 & \\
\hline CEV Convection Coefficient & $\mathrm{h}$ & 0.00825 & $\mathrm{~kW} / \mathrm{K}$ \\
\hline Allowable Vane Temperature & $\mathrm{T}_{\mathrm{w}}$ & 800 & $\mathrm{~K}$ \\
\hline
\end{tabular}

The results of increasing compressor pressure rations allowed by higher exit temperatures are presented in Table 5.

HPTV cooling allows for higher compression rations, greatly increasing system thrust and fuel efficiency. The analysis only considers the increase in pressure ratio - the impact this increase has on later cooling system loads, and the additional changes to the compressor required by this higher pressure flow are not considered.
Table 5 HPTV CEV Results

\begin{tabular}{|ccc|}
\hline & HPTV & No HPTV \\
\hline Thrust $(\mathrm{kN})$ & 115 & 92.5 \\
\hline TSFC $\left(\mathrm{kg} / \mathrm{kN} \times 10^{5}\right)$ & 1.016 & 1.263 \\
\hline
\end{tabular}

Integrating HPTV into the turbine vanes is significantly easier than into compressor vanes, due to the required airfoil geometry. Turbine airfoils have sufficient thickness to contain a wick and vapor chamber, while compressor airfoils have difficulty fitting these while maintaining structural integrity.

\subsection{Waste Heat Recovery}

Waste heat recovery is a common practice in land-based gas turbine systems. Combined cycle and cogeneration plants increase their overall efficiency by utilizing the waste heat from the gas turbine system to provide heating, or power secondary steam cycles. Young and Gupta (1980) proposed a similar system for turbofan engines, where heat is transferred from the main gas flow to the bypass air flow after the turbine. It was found that in certain cases this redistribution of energy increased the overall thrust provided by the engine. An analysis of a turbofan engine using HPTV to transfer heat from the main gas flow to the bypass flow was conducted. Input parameters for the turbofan system are presented in Table 6.

Table 6 HPTV Turbofan Waste Heat Recovery Inputs

\begin{tabular}{|llrll|}
\hline System Design Parameters & & & \\
\hline Fan Pressure Ratio & FPR & 4 & \\
\hline Bypass Ratio & BPR & 4 & \\
\hline Compressor Pressure Ratio & CPR & 12 & \\
\hline Compressor Inlet Parameters & & & \\
\hline Temperature & $\mathrm{T}_{0}$ & 225 & $\mathrm{~K}$ \\
\hline Pressure & $\mathrm{P}_{0}$ & 0.265 & $\mathrm{Bar}$ \\
\hline Mass Flow Rate & $\mathrm{m}$ & 90 & $\mathrm{~kg} / \mathrm{s}$ \\
\hline Combustor Parameters & & & \\
\hline Turbine Inlet Temperature & TIT & 1600 & $\mathrm{~K}$ \\
\hline Fuel Lower Heating Value & $\Delta \mathrm{H}_{\mathrm{f}}$ & 45000 & $\mathrm{~kJ} / \mathrm{kg}$ \\
\hline HPTV Parameters & & & \\
\hline Number of HPTV & $\mathrm{n}$ & 60 & \\
\hline Absolute Heat Pipe Resistance & $\mathrm{R}_{\mathrm{HP}}$ & 10000 & $\mathrm{~K} / \mathrm{kW}$ \\
\hline HPTV Convection Coefficient & $\mathrm{h}$ & 0.007 & $\mathrm{~kW} / \mathrm{K}$ \\
\hline Pressure Loss & $\mathrm{p}_{\text {loss, film }}$ & 2 & $\%$ \\
\hline & & & \\
\hline
\end{tabular}

A $2 \%$ pressure loss was assumed in the main and bypass flows due to the insertion of additional vanes into the fluid path. As there is fewer restraints on HPTV design in the waste heat recovery system, the thermal resistance values can be fine-tuned to achieve peak performance at specific operating conditions. Results of the analysis are presented in Table 7.

HPTV waste heat recovery vanes led to a $1.2 \%$ decrease in specific fuel consumption by redistributing energy from the main flow to the bypass flow. 
Table 7 HPTV Turbofan Waste Heat Recovery Results

\begin{tabular}{|ccc|}
\hline & HPTV & No HPTV \\
\hline Thrust $(\mathrm{kN})$ & 49.1 & 48.5 \\
\hline TSFC $\left(\mathrm{kg} / \mathrm{kN} \times 10^{5}\right)$ & 1.226 & 1.241 \\
\hline
\end{tabular}

\section{CONCLUSIONS}

HPTV offer significant performance increases in a variety of applications within turbofan engines, compared to conventional film cooling methods.

HPTV offer improved cooling, with a more uniform temperature distribution across the airfoil. HPTV eliminate the need for bleed air from the compressor for cooling and allow for greater control over hot gas flow by removing the interference caused by a cool air film. In design, the removal of the cooling film makes computational analysis of flow across turbine vanes easier, allowing for faster analysis and development of turbofan engines. Removal of the film cooling passages in the turbine vane allows for a greater variety of fuels to be employed, as there is no threat of cool air passage blockage due to particulates from some alternative fuels.

Due to the proximity of the bypass air flow, turbofan engines are uniquely positioned to take advantage of HPTV compared to other gas turbine systems. HPTV improve many aspects of turbofan engine operation, including vane part life and fuel efficiency that are important to the aerospace industry. HPTV are a promising new method for vane cooling as engine temperatures continue to increase and alternative fuels see more development

\section{ACKNOWLEDGEMENTS}

This material is based upon work supported by the National Science Foundation under Grant No. 1744118 to the University of Connecticut.

\section{NOMENCLATURE}

$A$

F

$h$

$h_{f g}$

$H$

$\Delta H_{r} \quad$ Lower Heating Value $(\mathrm{kJ} / \mathrm{kg})$

$k \quad$ Thermal Conductivity $(\mathrm{W} / \mathrm{m} \cdot \mathrm{K})$

$L \quad$ Length (m)

$\dot{m} \quad$ Mass Flow Rate $(\mathrm{kg} / \mathrm{s})$

$n \quad$ Number of Heat Pipe Turbine Vanes

$P \quad$ Pressure $(\mathrm{Pa})$

$q \quad$ Heat Transfer Rate (W)

$r \quad$ Radius (m)

$r_{h} \quad$ Hydraulic Radius (m)

$R \quad$ Thermal Resistance $(\mathrm{K} / \mathrm{W})$

$R_{g} \quad$ Universal Gas Constant

$t \quad$ Thickness (m)

$T \quad$ Temperature (K)

$v \quad$ Specific Volume $\left(\mathrm{m}^{3} / \mathrm{kg}\right)$

$v_{f g} \quad$ Change in Specific Volume $\left(\mathrm{m}^{3} / \mathrm{kg}\right)$

$$
\begin{array}{ll}
V & \text { Velocity }(\mathrm{m} / \mathrm{s}) \\
W & \text { Work }(\mathrm{kJ})
\end{array}
$$

Greek Symbols

$\begin{array}{ll}\alpha & \text { Accommodation Coefficient } \\ \theta & \text { Central Angle (Degrees) } \\ \rho & \text { Density }\left(\mathrm{kg} / \mathrm{m}^{3}\right) \\ \mu & \text { Viscosity }(\mathrm{Pa} \cdot \mathrm{s})\end{array}$

$\begin{array}{ll}\text { Subscripts } & \\ a & \text { Axial } \\ a v g & \text { Average } \\ b & \text { Bypass } \\ c & \text { Condenser } \\ e & \text { Evaporator } \\ e f f & \text { Effective } \\ e x & \text { External } \\ i & \text { Inner } \\ i n & \text { Inlet } \\ i n t e r & \text { Interfacial } \\ m & \text { Main Flow } \\ o & \text { Outer } \\ l & \text { Liquid } \\ v & \text { Vapor } \\ w & \text { Wall } \\ w k & \text { Wick }\end{array}$

\section{REFERENCES}

Anderson, W.G., Hoff, S., Winstanley, D., Phillips, J., and DelPorte, S., 1993, "Heat Pipe Cooling of Turboshaft Engines," American Society of Mechanical Engineers 1993 International Gas Turbine and Aeroengine Congress and Exposition, V03AT15A071-V03AT15A071. https://doi.org/10.1115/93-GT-220

Benn, S.P., Poplaski, L.M., Faghri, A., and Bergman, T.L., 2016, "Analysis of Thermosyphon/Heat Pipe Integration for Feasibility of Dry Cooling for Thermoelectric Power Generation," Applied Thermal Engineering, 104, 358-374. https://doi.org/10.1016/j.applthermaleng.2016.05.045

Bergman, T.L., Incropera, F.P., Dewitt, D.P., and Lavine, A.S., 2011, Fundamentals of Heat and Mass Transfer, $7^{\text {th }}$ ed., John Wiley \& Sons, Hoboken, NJ.

Bogard, D.G., and Thole, K.A., 2006, "Gas Turbine Film Cooling," Journal of Propulsion and Power, 22(2), 249-270. https://doi.org/10.2514/1.18034

Day, C.R., Oldfield, M.L., Lock, G.D., and Dancer, S.N., 1998, "Efficiency Measurements of an Annular Nozzle Guide Vane Cascade with Different Film Cooling Geometries," American Society of Mechanical Engineers 1998 International Gas Turbine and Aeroengine Congress and Exhibition, V004T09A088-V004T09A088. https://doi.org/10.1115/98-GT-538

Faghri, A., and Bergman, T. L., 2017, "Reviews of Advances in Heat Pipe Analysis and Numerical Simulation," Numerical Simulation of Heat 
Exchangers: Advances in Numerical Heat Transfer, $1^{\text {st }}$ ed., 5, 173-212, CRC Press, Boca Raton, FL.

https://doi.org/10.1201/9781315372587

Faghri, A., 2016, Heat Pipe Science and Technology, $2^{\text {nd }}$ ed., Global Digital Press.

Gauntner, D.J., and Sucec, J., 1978, "Method for Calculating Convective Heat-Transfer Coefficients over Turbine Vane Surfaces," NASA Technical Paper 1134.

Han, J.C., 2013, "Fundamental Gas Turbine Heat Transfer," Journal of Thermal Science and Engineering Applications, 5(2), 021007. https://doi.org/10.1115/1.4023826

Han, J.C., Dutta, S., and Ekkad, S., 2012, Gas Turbine Heat Transfer and Cooling Technology, $2^{\text {nd }}$ ed., CRC Press, Boca Raton, FL. https://doi.org/10.1201/b13616

Kumar, S., and Singh, O., 2008, "Thermodynamic Evaluation of Different Gas Turbine Blade Cooling Techniques," Second International Conference on Thermal Issues in Emerging Technologies, 237-244. https://doi.org/10.1109/THETA.2008.5167172

Langston, L., and Faghri, A., 1995, "Heat Pipe Turbine Vane Cooling”, Advanced Turbine Systems Annual Program Review, 1-9.

Lindemuth, J.E., and Anderson, W.G., 1999, U.S. Patent No. 5,975,841, Washington, DC: U.S. Patent and Trademark Office.

Louis, J.F., Hiraoka, K., and El Masri, M.A., 1983, "A Comparative Study of the Influence of Different Means of Turbine Cooling on Gas Turbine Performance," American Society of Mechanical Engineers 1983 International Gas Turbine Conference and Exhibit, V003T05A010V003T05A010.

https://doi.org/10.1115/83-GT-180

McGarry, J., 1978, UK Patent No. 1,516,041, London: Patent Office.

Norris, J.W., Hill, J.D., and Nordeen, C.A., 2011, U.S. Patent No. 7,966,807, Washington, DC: U.S. Patent and Trademark Office.

Pollock, T.M., and Tin, S., 2006, "Nickel-based Superalloys for Advanced Turbine Engines: Chemistry, Microstructure and Properties," Journal of Propulsion and Power, 22(2), 361-374.

https://doi.org/10.2514/1.18239

Pritchard, L. J., 1985, “An Eleven Parameter Axial Turbine Airfoil Geometry Model," American Society of Mechanical Engineers 1985 International Gas Turbine Conference and Exhibit, V001T03A058-
V001T03A058.

https://doi.org/10.1115/85-GT-219

Shabgard, H., Allen, M.J., Sharifi, N., Benn, S.P., Faghri, A., and Bergman, T.L., 2015, "Heat Pipe Heat Exchangers and Heat Sinks: Opportunities, Challenges, Applications, Analysis, and State of the Art," International Journal of Heat and Mass Transfer, 89, 138-158. https://doi.org/10.1016/j.ijheatmasstransfer.2015.05.020

Silverstein, C.C., Gottschlich, J.M., and Meininger, M., 1994, "The Feasibility of Heat Pipe Turbine Vane Cooling," American Society of Mechanical Engineers 1994 International Gas Turbine and Aeroengine Congress and Exposition, V004T09A046-V004T09A046. https://doi.org/10.1115/94-GT-306

Sundaram, N., and Thole, K.A., 2007, "Effects of Surface Deposition, Hole Blockage, and Thermal Barrier Coating Spallation on Vane Endwall Film Cooling," Journal of Turbomachinery, 129(3), 599-607. https://doi.org/10.1115/1.2720485

Young, P., and Gupta, P., 1980, UK Patent No. 2,041,090, Newport, South Wales: UK Intellectual Property Office.

Zuo, Z.J., Faghri, A., and Langston, L., 1998, "Numerical Analysis of Heat Pipe Turbine Vane Cooling," Journal of Engineering for Gas Turbines and Power, 120(4), 735-743.

https://doi.org/10.1115/1.2818461A

\section{APPENDIX A: HEAT PIPE TURBINE VANE THERMAL RESISTANCES}

Equations for the HPTV thermal resistances shown in Fig. 2 are presented in Table A-1. Equations are adapted from Shabgard et al. (2015) for a vane geometry.

The wall and wick thermal resistances are obtained by adding several thermal resistances in parallel, one for each of the equations used to define the HPTV geometry. The Arc equation can be used for the leading edge, trailing edge, and suction surface arcs. The Polynomial equation can be used for the suction and pressure surface polynomials. Polynomial and arc sections of the HPTV are shown in Figure B-1.

Values for the convective heat transfer coefficient are based on the Integrated High Performance Turbine Engine Technology Phase II turboshaft engine (National Research Council, 2007). Convective heat transfer coefficient values for this engine design, including the effects of thermal barrier coating, are presented in Anderson (1993).

These component thermal resistances can be added to get the total heat pipe thermal resistance with Eq. (A-1).

$$
R_{\mathrm{HP}}=\frac{\left[R_{w, e}+R_{w, c}+\frac{\left(R_{w k, e}+R_{\text {inter }, e}+R_{v}+R_{\text {inter }, c}+R_{w k, c}\right)\left(R_{a, w k}\right)}{\left(R_{w k, e}+R_{\text {inter }, e}+R_{v}+R_{\text {inter }, c}+R_{w k, c}\right)+\left(R_{a, w k}\right)}\right]\left(R_{a, w}\right)}{\left[R_{w, e}+R_{w, c}+\frac{\left(R_{w k, e}+R_{\text {inter }, e}+R_{v}+R_{\text {inter }, c}+R_{w k, c}\right)\left(R_{a, w k}\right)}{\left(R_{w k, e}+R_{\text {inter }, e}+R_{v}+R_{\text {inter }, c}+R_{w k, c}\right)+\left(R_{a, w k}\right)}\right]+\left(R_{a, w}\right)}
$$

The external thermal resistances can then be added in series to get the total resistance.

$$
R_{t o t}=R_{H P}+R_{e x, c}+R_{e x, e} \quad(A-2)
$$

\section{APPENDIX B: HEAT PIPE TURBINE VANE GEOMETRIC MODEL}

Pritchard (1985) developed an 11-parameter airfoil model, which describes the airfoil geometry using three arcs and two $3^{\text {rd }}$ order polynomials. Five critical points on the vane are found, and then connected using the arc and polynomial equations. This methodology is expanded for HPTV to accommodate the wall and wick thicknesses. Fig. (B-1) shows a HPTV cross section created using this method.

Points 1-5 represent the critical points. The vane is defined in a Cartesian coordinate system, with the $\mathrm{x}$-axis parallel to the axial chord and the $y$-axis parallel to the tangential chord.

To expand the methodology to HPTV, the wall-wick boundary and wickvapor chamber boundary must be added. This is done numerically, by finding the line normal to each point in the outer wall. Points are plotted on these lines at the wall thickness and wall + wick thickness to create the inner two boundaries. 
Table A-1 HPTV Thermal Resistances

\begin{tabular}{|c|c|c|}
\hline Thermal Resistance & Description & Equation \\
\hline \multicolumn{3}{|c|}{ Axial Thermal Resistances } \\
\hline $\mathbf{R}_{\mathbf{a}, \mathbf{w}}$ & Axial conduction in wall & $\frac{L_{e f f}}{A_{w} k_{w}}$ \\
\hline $\mathbf{R}_{\mathbf{a}, \mathbf{w k}}$ & Axial conduction in wick & $\frac{L_{e f f}}{A_{w k} k_{w k}}$ \\
\hline \multicolumn{3}{|c|}{ Condenser Section Thermal Resistances } \\
\hline $\mathbf{R}_{\mathbf{w}, \mathbf{c}}$ & Radial conduction in wall & Arc: $: \frac{\theta}{360} \frac{L_{c}}{\pi\left(r_{0}^{2}-r_{i}^{2}\right) k_{w}}$, Polynomial: $\frac{1}{k_{w}} \int_{t_{1}}^{t_{2}} \frac{d t}{A(t)}$ \\
\hline $\mathbf{R}_{\mathbf{w k}, \mathbf{c}}$ & Radial conduction in wick & Arc: $\quad \frac{\theta}{360} \frac{L_{c}}{\pi\left(r_{0}^{2}-r_{i}^{2}\right) k_{w k}}$, Polynomial: $\frac{1}{k_{w k}} \int_{t_{1}}^{t_{2}} \frac{d t}{A(t)}$ \\
\hline $\mathbf{R}_{\text {inter,c }}$ & Wick-vapor interface & $\frac{1}{h_{\text {inter }} A_{\text {inter }, c}}, h_{\text {inter }}=\left(\frac{2 \alpha}{2-\alpha}\right)\left(\frac{h_{f g}^{2}}{T_{v} v_{f g}}\right) \sqrt{\frac{1}{2 \pi R_{g} T_{v}}}\left(1-\frac{P_{v} v_{f g}}{2 h_{f g}}\right)$ \\
\hline \multicolumn{3}{|c|}{ Evaporator Section Thermal Resistances } \\
\hline $\mathbf{R}_{\mathbf{w}, \mathbf{e}}$ & Radial conduction in wall & Arc: $\quad \frac{\theta}{360} \frac{L_{e}}{\pi\left(r_{0}^{2}-r_{i}^{2}\right) k_{w}}$, Polynomial: $\frac{1}{k_{w}} \int_{t_{1}}^{t_{2}} \frac{d t}{A(t)}$ \\
\hline $\mathbf{R}_{\mathbf{w k}, \mathbf{e}}$ & Radial conduction in the liquid film/wick & Arc: $\frac{\theta}{360} \frac{L_{e}}{\pi\left(r_{0}^{2}-r_{i}^{2}\right) k_{w k}}$, Polynomial: $\frac{1}{k_{w k}} \int_{t_{1}}^{t_{2}} \frac{d t}{A(t)}$ \\
\hline $\mathbf{R}_{\text {inter,e }}$ & Wick/fluid-vapor interface & $\frac{1}{h_{\text {inter }} A_{\text {inter }, e}}, h_{\text {inter }}=\left(\frac{2 \alpha}{2-\alpha}\right)\left(\frac{h_{f g}^{2}}{T_{v} v_{f g}}\right) \sqrt{\frac{1}{2 \pi R_{g} T_{v}}}\left(1-\frac{P_{v} v_{f g}}{2 h_{f g}}\right)$ \\
\hline \multicolumn{3}{|c|}{ Vapor Region Thermal Resistance } \\
\hline $\mathbf{R}_{\mathbf{v}}$ & Vapor thermal resistance & $\frac{8 R_{g} \mu_{v} T_{v}^{2}}{\pi h_{f g}^{2} P_{v} \rho_{v}}\left[\frac{L_{e f f}}{r_{h}^{4}}\right]$ \\
\hline \multicolumn{3}{|c|}{ External Thermal Resistances } \\
\hline Rex,c & Condenser external convection & $\frac{A_{H P T V, c}}{h_{e x, c}}$ \\
\hline Rex,e & Evaporator external convection & $\frac{A_{H P T V, e}}{h_{e x, e}}$ \\
\hline
\end{tabular}

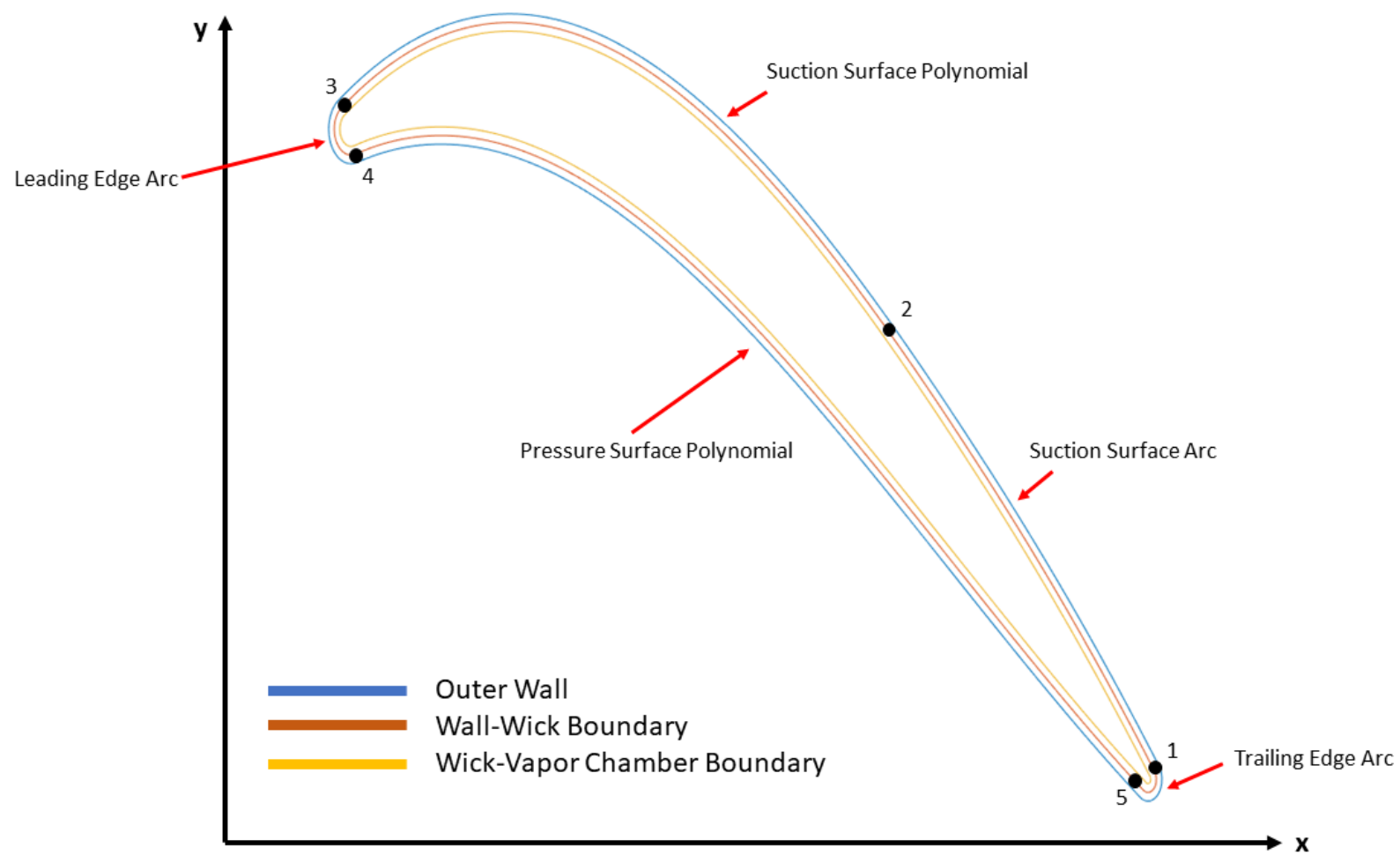

Fig. B-1 HPTV Geometry Diagram 